\title{
Acute Kidney Injury after Cardiac Surgery in Patients Without Chronic Kidney Disease
}

\author{
Kátia Alves Ramos ${ }^{1}, \mathrm{MD} ;$ Cristiane Bitencourt Dias $^{2}, \mathrm{MD}, \mathrm{PhD}$
}

DOI: $10.21470 / 1678-9741-2018-0084$

\begin{abstract}
Introduction: Among patients undergoing cardiac surgery, the occurrence of acute renal injury appears to be associated with worse prognosis and increased mortality. The objective of this study was to evaluate risk factors and the impact this complication on mortality and survival after cardiac surgery among patients without chronic kidney disease.

Methods: In this retrospective study, we reviewed the medical records of 142 patients who underwent elective coronary artery bypass grafting, valve replacement (single or multiple), or both (simultaneously) at a tertiary care hospital.

Results: Among the 142 patients evaluated, the mean age was $58.28 \pm 13.87$ years and $80(56.33 \%)$ were female. The postoperative incidence of acute renal injury was $43.66 \%$. Univariate analysis between the groups with and without acute renal injury revealed no significant differences, whereas multivariate analysis showed that risk factors for acute renal
\end{abstract}

injury included valve replacement $(O R=4.7, P=0.002,95 \%$ $\mathrm{Cl}=1.76-12.62$, age (OR=1.044, $P=0.012,95 \% \mathrm{Cl}=1.01-1.07)$, previous cardiac surgery $(\mathrm{OR}=36.1, P=0.015,95 \% \mathrm{Cl}=1.99-653.85)$, postoperative use of the vasoactive drug norepinephrine (OR=3.32, $P=0.013,95 \% \mathrm{Cl}=1.29-8.58)$ and dobutamine (OR=5.3, $P=0.019,95 \% \mathrm{Cl}=1.32-21.64)$. In our sample, there were 30 deaths, of which 25 had acute kidney injury. Survival was also lower among the patients with this complication, especially those who had required hemodialysis $(\mathrm{OR}=2.60, P<0.001,95 \% \mathrm{Cl}=1.01-6.70)$ or had previously undergone cardiac surgery $(O R=3.68, P<0.001$, 95\% $\mathrm{Cl}=1.09-12.37)$.

Conclusion: Our findings underscore the importance of identifying risk factors for developing acute renal injury after cardiac surgery, which can further the development of effective renoprotective strategies.

Keywords: Acute Kidney Injury. Thoracic Surgery. Cardiac Surgical Procedures. Risk Factors. Mortality.

\section{Abbreviations, acronyms \& symbols}

$\begin{array}{ll}\text { AKI } & =\text { Acute renal injury } \\ \text { AKIN } & =\text { Acute Kidney Injury Network } \\ \text { CABG } & =\text { Coronary artery bypass grafting } \\ \text { COPD } & =\text { Chronic obstructive pulmonary disease } \\ \text { CPB } & =\text { Cardiopulmonary bypass } \\ \text { ICU } & =\text { Intensive care unit } \\ \text { MAP } & =\text { Mean arterial pressure }\end{array}$

\section{INTRODUCTION}

Acute renal injury (AKI) is a severe complication that occurs in 3.5-31.0\% of patients undergoing cardiac surgery, making it one of the most common complications observed in this group of patients $^{[1]}$. In a study conducted by Kochi et al. ${ }^{[2]}$, the prevalence of postoperative AKI among cardiac surgery patients was 34.0\%. In contrast, Santos et al. ${ }^{[3]}$, Chertow et al. ${ }^{[4]}$ and Conlon et al. ${ }^{[5]}$, reported rates of only $16.1 \%, 2.4 \%$, and $1.1 \%$, respectively. The considerable variation in the reported incidence and prevalence of AKI as a postoperative complication of cardiac surgery is due to differences in the diagnostic criteria adopted, as well as in study design, inclusion/exclusion criteria, patient profiles, and the type/number of treatment facilities involved ${ }^{[6]}$.

Evidence suggests that even slight postoperative increases in serum creatinine levels are associated with a significant increase in the risk of death ${ }^{[7]}$. Among individuals undergoing cardiac surgery, mortality has been reported to be as high as $8 \%$ and postoperative $\mathrm{AKI}$ can increase the mortality rate to over $60 \%{ }^{[7]}$. The occurrence of $\mathrm{AKI}$ in patients undergoing cardiac surgery raises the mortality rate from $0.4-4.4 \%$ to $1.3-22.3 \%$; when those same patients require dialysis, rates range from $25 \%$
${ }^{1}$ Centro Universitário Patos de Minas (UNIPAM), Patos de Minas, MG, Brazil. ${ }^{2}$ Instituto de Assistência Médica do Servidor Público de São Paulo (IAMSPE), São Paulo, SP, Brazil.

This study was carried out at Centro Universitário Patos de Minas (UNIPAM), Patos de Minas, MG, Brazil.
Correspondence Address:

Kátia Alves Ramos

Centro Universitário Patos de Minas

Rua Carajás, 846 - Patos de Minas, MG, Brazil

Zip code: 38702-188

E-mail:katiaramos@unipam.edu.br 
to $88.9 \%$, making severe postoperative AKI an independent risk factor for mortality that results in an 8-fold increase in the risk of death ${ }^{[8,9]}$. Therefore, cardiac surgery AKI is associated with serious complications as well as with prolonged intensive care unit (ICU) stays and with a worse quality of life. It also increases early and late mortality and health care expenditures ${ }^{[10,11]}$.

The early identification of patients at risk of developing AKI after cardiac surgery is an important strategy for improving the care of such patients during the intraoperative and postoperative periods. The following factors have been found to facilitate the development of AKI after cardiac surgery: age; obesity; female gender; valve replacement surgery; myocardial infarction in the last 30 days; low cardiac output; blood transfusion; prolonged cardiopulmonary bypass (CPB); the use of inotropic or vasoconstrictor drugs; the use of an intra-aortic balloon pump; diabetes mellitus; heart failure; chronic obstructive pulmonary disease (COPD); peripheral artery disease; systemic arterial hypertension; and chronic kidney disease $\mathrm{e}^{[3,8,12-15]}$.

Epidemiological studies of AKI in cardiac surgery patients are important because they allow for better diagnosis of AKI and facilitate the prognosis estimation, as well as the development of new, more effective strategies to prevent and minimize this complication, thus reducing the associated morbidity and mortality ${ }^{[16]}$. Therefore, the objective of this study was to identify the risk factors for AKI in cardiac surgery patients without chronic kidney disease, as well as to assess the impact of AKI on the early mortality and survival of such patients, at a single cardiology center in the Southeastern region of Brazil.

\section{METHODS}

\section{Study Population}

This was a retrospective study of patients between 20 and 80 years of age who underwent coronary artery bypass grafting (CABG), valve replacement (single or multiple), or both (simultaneously), between January 2008 and January 2014. All the procedures had been performed at a tertiary care cardiology hospital that serves the public and private sector in the macroregion of Alto Paranaíba, in the Brazilian state of Minas Gerais.

\section{Exclusion Criteria}

Patients who underwent cardiac surgery for congenital heart disease and emergency heart surgery were excluded. We also excluded patients who, within the last 72 hours before surgery, were injected with iodinated contrast (because of its potential nephrotoxicity), as well as those with a preoperative creatinine clearance $<60 \mathrm{~mL} / \mathrm{min}$ (as calculated by the Cockcroft-Gault equation) and those who died within the first 24 hours after surgery. There was only one patient undergoing CABG surgery without CPB, so this case was excluded.

We reviewed the medical records of 195 patients who underwent cardiac surgery during the studied period. Of those 195 records, 51 were incomplete. Therefore, the final sample comprised 144 medical records. In the process of constructing the multivariate analysis (logistic regression) models, it was necessary to exclude two cases, because they were considered outliers in practically all analyses. Thus, the final analysis comprised
142 medical records. After analyzing the medical records, we contacted all individuals or the relatives by telephone, in order to obtain information about subsequent survival or mortality.

\section{Variables Studied}

- For the preoperative period, we evaluated physical characteristics (gender, age, weight, and height), biochemical characteristics (prior complete blood count and baseline serum creatinine), and comorbidities (arterial hypertension, diabetes mellitus, coronary heart disease, and (OPD), as well as the history of stroke, coronary artery disease, and cardiac surgery;

- For the perioperative period, we evaluated the type of surgery performed $(C A B G$, valve replacement, or the combination of the two), the duration of $(\mathrm{PB}$, the need for transfusion of blood products, and the use of vasoactive drugs (norepinephrine or dobutamine);

- For the postoperative period, we evaluated the results of the complete blood counts, serum creatinine, and serum urea-on postoperative days 1 and 2, as well as on the day of hospital discharge. We also evaluated mean arterial pressure (MAP), diuresis, and fluid balance on postoperative days 1 and 2, as recorded on forms filled out daily by the nursing staff;

- The need for blood transfusion, the use of vasoactive drugs (norepinephrine or dobutamine), the administration of diuretics, and the need for hemodialysis were evaluated;

- We noted the length of the ICU stay (in days) and whether the patient died or was discharged.

\section{Definition of Terms}

- AKI was defined according to the Acute Kidney Injury Network (AKIN) classification, using serum creatinine and urine output as criteria for the evaluation of renal function. The AKIN classifies patients as stage 1, stage 2, or stage 3, according to the worst serum creatinine or urine output over a 48-hour period. Patients who require hemodialysis are classified as AKIN stage $3^{[17]}$;

- The preoperative period was defined as the time from the scheduling of the surgery to the arrival of the patient in the operating room;

- The perioperative period was defined as the time from the arrival of the patient in the operating room to ICU admission;

- The postoperative period was defined as the time from ICU admission to hospital discharge;

- Early mortality was defined as death occurring within the first 30 days after surgery;

- Late mortality was defined as death occurring $\geq 31$ days after surgery up to the final follow-up period of three years;

- When necessary, hemodialysis was intermittent because this is the only type of service available;

- The research project was approved by the Research Ethics Committee (number 718380) of the Instituto de Assistência Médica ao Servidor Público (Institute for the Medical Care of Civil Servants) and registered at Plataforma Brasil (number CAAE 00555512.7.0000.5463). 


\section{Statistical Analysis}

All statistical analysis were performed on the IBM SPSS Statistics software package, version 22.0 (IBM Corporation, Armonk, NY, USA). The statistical analysis was carried out in two stages.

Continuous variables were compared with the Student's t-test, and categorical variables were compared with the chisquare test. Once these variables had been listed, multiple logistic regression was used in order to examine the influence of all variables simultaneously and their relation to the occurrence of AKI. In the process of constructing the multivariate analysis (logistic regression) models, it was necessary to exclude two cases, because they were considered outliers in practically all analyses. Therefore, the final analysis comprised 142 medical records.

In the second stage, we evaluated the impact of AKI on mortality and survival. We used the chi-square test to evaluate the impact of AKI on mortality and the Mantel-Haenszel method (common odds ratio) to evaluate the probability of death due to $\mathrm{AKI}$ in the postoperative period. Subsequently, the Kaplan-Meier method was applied to compare the patients who developed AKI after cardiac surgery with those who did not, in terms of survival, and Cox regression was used to determine if there were other variables that directly affected survival. The outcome measure (mortality) was evaluated for a maximum of 3 years after cardiac surgery. Values of $P<0.05$ were considered statistically significant.

\section{RESULTS}

\section{Descriptive Analysis}

In the sample $(n=142)$, the mean age was $58.28 \pm 13.87$ years, the mean body mass index was $26.05 \pm 5.82 \mathrm{~kg} / \mathrm{m}^{2}$ and 80 (56.33\%) were female. The most common surgical procedure was valve replacement alone, which was performed in 81 cases (57.05\%), followed by isolated CABG, performed in 56 (39.43\%), and the combination of the two, performed in 5 (3.52\%). The mean duration of CPB was $54.58 \pm 20.60$ minutes. The mean serum creatinine level was $1.09 \pm 0.29 \mathrm{mg} / \mathrm{dL}$ at baseline, $1.50 \pm 0.51$ $\mathrm{mg} / \mathrm{dL}$ on postoperative day 1 , and $1.57 \pm 0.89 \mathrm{mg} / \mathrm{dL}$ on postoperative day 2. The mean serum urea level was 39.71 \pm 16.57 $\mathrm{mg} / \mathrm{dL}$ at baseline, $51.80 \pm 21.72 \mathrm{mg} / \mathrm{dL}$ on postoperative day 1 , and $66.48 \pm 27.56 \mathrm{mg} / \mathrm{dL}$ on postoperative day 2. Preoperative laboratory tests showed a mean hemoglobin of $12.98 \pm 6.55 \mathrm{~g} / \mathrm{dL}$ and a mean hematocrit of $37.40 \pm 4.78 \%$. On postoperative days 1 and 2 , the mean hemoglobin was $10.92 \pm 7.42 \mathrm{~g} / \mathrm{dL}$ and $9.66 \pm 1.72$ $\mathrm{g} / \mathrm{dL}$, respectively, and the mean hematocrit was $31.24 \pm 5.05 \%$ and $29.31 \pm 5.17 \%$, respectively.

Among the patients evaluated, the mean MAP on postoperative days 1 and 2 was $74.05 \pm 10.38 \mathrm{mmHg}$ and $76.12 \pm 10.53 \mathrm{mmHg}$, respectively. On postoperative days 1 and 2 , the mean urine output was $2476.13 \pm 1067.61 \mathrm{ml} /$ day and $1437.25 \pm 968.92 \mathrm{ml} /$ day respectively.

The frequency of AKI of any degree within the first 48 hours after cardiac surgery was 43.66\%, AKI occurring in 62 patients, of whom 36 (58.06\%) were classified as AKIN stage 1, whereas 5 (8.06\%) were classified as AKIN stage 2, and 21 (33.8\%) were classified as AKIN stage 3. Among the 62 patients who developed
AKI, hemodialysis was required for 12 (19.35\%). In the sample as a whole, the mean ICU stay was $4.4 \pm 2.4$ days. The other descriptive variables are shown in Table 1.

\section{Comparison Between the Patients With and Without AKI}

The patients with AKI ( $n=62)$ did not differ significantly from those without AKI $(n=80)$ in terms of the mean age $-59.92 \pm 14.19$ years vs. $57.01 \pm 13.57$ years $(P=0.18)$; the mean duration of $C P B-$ 50 (range, 40-70) minutes vs. 50 (range, 40-60) minutes ( $P=0.10$ ); the mean preoperative serum creatinine - 1.07 (range, 0.86-1.29) $\mathrm{mg} / \mathrm{dL}$ vs. 1.00 (range, 0.90-1.24) mg/dL ( $P=0.99$ ); and the mean preoperative serum urea-38.00 (range, 30.00-47.75) $\mathrm{mg} / \mathrm{dL}$ vs. 35.50 (range, 29.25-43.00) $\mathrm{mg} / \mathrm{dL}(P=0.36)$. We also found no significant difference between the patients with and without AKI in terms of the mean MAP on postoperative day 1-72.5 (range, 65.0-80.0) mmHg vs. 70.0 (range, 68.0-85.0) mmHg ( $P=0.36)$-or on postoperative day 2-75.0 (range, 65.0-85.0) $\mathrm{mmHg}$ vs. 75.0 (range, 68.5-85.0) $\mathrm{mmHg}(P=0.36)$. On postoperative day 1 , the patients with and without AKI did not differ significantly in terms of the mean fluid balance-100.0 (range, -301.0 to 880.8 ) $\mathrm{mL}$ vs. 288.0 (range, -250.0 to 1439.0$) \mathrm{mL}(P=0.34)$ —nor was there

Table 1. Descriptive analysis of the preoperative, perioperative, and postoperative variables studied in 142 patients undergoing cardiac surgery.

\begin{tabular}{l|c}
\hline Variables & $\mathbf{n}(\%)$ \\
\hline Comorbidities & \\
\hline Systemic arterial hypertension & $67(47.18)$ \\
\hline Diabetes mellitus & $39(27.46)$ \\
\hline History of cardiac surgery & $10(7.04)$ \\
\hline History of coronary heart disease & $61(42.95)$ \\
\hline History of stroke & $3(2.11)$ \\
\hline Chronic obstructive pulmonary disease & $18(12.67)$ \\
\hline
\end{tabular}

Perioperative use of blood products and amines

\begin{tabular}{l|c}
\hline Fresh-frozen plasma & $17(11.97)$ \\
\hline Packed red cells & $3(2.11)$ \\
\hline Packed platelets & $20(14.08)$ \\
\hline Cryoprecipitate & $3(2.11)$ \\
\hline Norepinephrine & $7(4.92)$ \\
\hline Dobutamine & $6(4.22)$ \\
\hline
\end{tabular}

Postoperative use of blood products and amines

\begin{tabular}{l|l}
\hline Packed red cells & $41(28.87)$ \\
\hline Norepinephrine & $48(33.80)$ \\
\hline Dobutamine & $30(21.12)$ \\
\hline Diuretics & $97(68.30)$ \\
\hline
\end{tabular}


Table 2. Clinical and laboratorial differences between patients with and without acute kidney injury (AKI).

\begin{tabular}{|c|c|c|c|c|}
\hline \multicolumn{2}{|c|}{ Clinical and laboratorial characteristics } & $\begin{array}{l}\text { Patients with AKI } \\
n=62\end{array}$ & $\begin{array}{l}\text { Patients without AKI } \\
\qquad n=80\end{array}$ & $P$ \\
\hline \multicolumn{2}{|l|}{ Age (years) } & $59.92 \pm 14+19$ & $57.01 \pm 13.57$ & 0.18 \\
\hline \multirow{3}{*}{ Type of surgical procedure (\%) } & CABG & 30.62 & 46.25 & 0.11 \\
\hline & Valve replacement & 64.61 & 51.25 & 0.11 \\
\hline & Combination & 4.83 & 2.56 & 0.11 \\
\hline \multicolumn{2}{|l|}{ CPB (minutes) } & $50(40-70)$ & $50(40-60)$ & 0.10 \\
\hline \multicolumn{2}{|c|}{ Preoperative serum creatinine (mg/dl) } & $1.07(0.86-1.29)$ & $1.00(0.91-1.24)$ & 0.99 \\
\hline \multicolumn{2}{|l|}{ Preoperative serum urea (mg/dl) } & $38(30-47.75)$ & $35.50(29.25-43)$ & 0.36 \\
\hline \multicolumn{2}{|l|}{ MAP $(\mathrm{mmHg})$ day 1} & $72.50(65-80)$ & $70(68-85)$ & 0.36 \\
\hline \multicolumn{2}{|l|}{ MAP $(\mathrm{mmHg})$ day 2} & $75(65-85)$ & $75(68.50-85)$ & 0.36 \\
\hline \multicolumn{2}{|l|}{ Fluid balance $(\mathrm{ml})$} & $100(-301-880.80)$ & $288(-250-1439)$ & 0.34 \\
\hline \multicolumn{2}{|c|}{ Perioperative transfusion of blood products (\%) } & 90.30 & 82.50 & 0.22 \\
\hline \multicolumn{2}{|c|}{ Postoperative norepinephrine use (\%) } & 48.38 & 22.50 & 0.0008 \\
\hline \multicolumn{2}{|c|}{ Postoperative dobutamine use (\%) } & 37.09 & 8.80 & $<0.0001$ \\
\hline
\end{tabular}

$\mathrm{CABG}=$ coronary artery bypass grafting; $\mathrm{CPB}=$ cardiopulmonary bypass; $\mathrm{MAP}=$ mean arterial pressure

any significant difference between the two groups in terms of the perioperative transfusion of blood products, which occurred in $90.3 \%$ of the patients with $\mathrm{AKI}$ and in $82.5 \%$ of those without $(P=0.22)$. In the postoperative period, norepinephrine was used in $30(48.38 \%)$ of the 62 patients with AKI and in 18 (22.5\%) of the 80 patients without $(P=0.0008)$, whereas dobutamine was used in $23(37.09 \%)$ of the 62 patients with $\mathrm{AKI}$ and in 7 (8.8\%) of the 80 patients without $(P<0.0001)$.

We found no significant difference between the patients with and without AKI in terms of the type of surgical procedure performed, isolated CABG being performed in 19 (30.64\%) of the 62 patients with AKI and in 37 (46.25\%) of the 80 patients without, valve replacement alone being performed in 40 (64.51\%) and 41 (51.25\%), respectively, and the combination of the two being performed in $3(4.83 \%)$ and 2 (2.5\%), respectively ( $P=0.11$ for all) (Table 2). However, analyzing a possible relationship between the type of surgery and the need for the use of dobutamine in the postoperative period, we observed that a smaller number of patients undergoing $C A B G$ required dobutamine in the postoperative period than did those undergoing valve replacement or the combination of the two procedures (Table 3 ).

There was no significant difference between the patients with and without AKI in terms of the proportion of individuals with diabetes mellitus, which was reported in 32.36\% $(n=20)$ and $23.75 \%$ ( $n=19)$, respectively ( $P=0.22$ ). We also found no significant difference between the patients with and without AKI in terms of the number of patients with a history of heart surgery ( $n=7 \mathrm{vs}$. $\mathrm{n}=3, P=0.09)$.

\section{Multivariate Analysis (Logistic Regression)}

We evaluated 142 medical records of patients who underwent cardiac surgery. The variables potentially associated with the risk of developing AKI in the postoperative period are shown in Table 4. We found that undergoing valve replacement was a risk factor for postoperative AKI, as were advanced age, having previously undergone cardiac surgery, and postoperative vasoactive drug use.

Table 3. Relationship between the type of cardiac surgery and the need for dobutamine use in the postoperative period.

\begin{tabular}{l|c|c|c}
\hline \multirow{2}{*}{ Postoperative dobutamine use } & CABG & Valve replacement & Both \\
\cline { 2 - 4 } & $\mathbf{( n = 5 6 )}$ & $\mathbf{( n = 8 1 )}$ & (n=5) \\
\hline Yes $(n)$ & 6 & 20 & 4 \\
\hline No $(n)$ & 50 & 61 & 1 \\
\hline
\end{tabular}

$\mathrm{CABG}=$ coronary artery bypass grafting

$P=0.0007$ vs. valve replacement and the combination of both procedures. 
Table 4. Multivariate analysis of risk factors associated with the development of acute kidney injury after cardiac surgery.

\begin{tabular}{l|c|c|c|c|c|c|c}
\multicolumn{1}{c|}{ Variable } & $\boldsymbol{\beta}$ & S.E. & Wald & df & $\boldsymbol{P}$ & OR & $\mathbf{9 5 \%}$ Cl \\
\hline Age & 0.043 & 0.017 & 6.257 & 1 & 0.012 & 1.044 & $1.01-1.079$ \\
\hline CABG & & & 10.303 & 2 & 0.006 & $1.00-1.000$ \\
\hline Valve replacement & 1.549 & 0.503 & 9.467 & 1 & 0.002 & 4.706 & $1.76-12.615$ \\
\hline CABG + valve replacement & -0.427 & 1.262 & 0.115 & 1 & 0.735 & 0.652 & $0.05-7.741$ \\
\hline History of cardiac surgery & 3.586 & 1.478 & 5.892 & 1 & 0.015 & 36.106 & $1.99-653.851$ \\
\hline Perioperative blood transfusion & -3.742 & 1.034 & 13.098 & 1 & $<0.001$ & 0.024 & $0.00-0.180$ \\
\hline Postoperative use of packed red cells & 3.640 & 2.340 & 2.421 & 1 & 0.120 & 38.108 & $0.39-3738.351$ \\
\hline Perioperative use of norepinephrine & 3.376 & 1.764 & 3.662 & 1 & 0.056 & 29.264 & $0.92-928.379$ \\
\hline Postoperative use of norepinephrine & 1.201 & 0.484 & 6.156 & 1 & 0.013 & 3.322 & $1.29-8.582$ \\
\hline Postoperative use of dobutamine & 1.677 & 0.713 & 5.536 & 1 & 0.019 & 5.349 & $1.32-21.639$ \\
\hline Constant & -4.152 & 1.191 & 12.148 & 1 & 0.000 & 0.016 & $0.00-0.162$ \\
\hline
\end{tabular}

$\mathrm{CABG}=$ coronary artery bypass grafting

\section{Impact on Mortality and Survival Analysis}

During the three-year period evaluated, there were 30 deaths in our sample, 17 (56.66\%) of those deaths occurring in the first 30 days after cardiac surgery. Early and late mortality were higher among the patients with AKI than among those without, early mortality occurring in 15 and 2 of the patients, respectively $(P<0.04)$ and late mortality (death occurring $\geq 31$ days after surgery) in 10 and 3 of the patients, respectively $(P<0.04)$. The

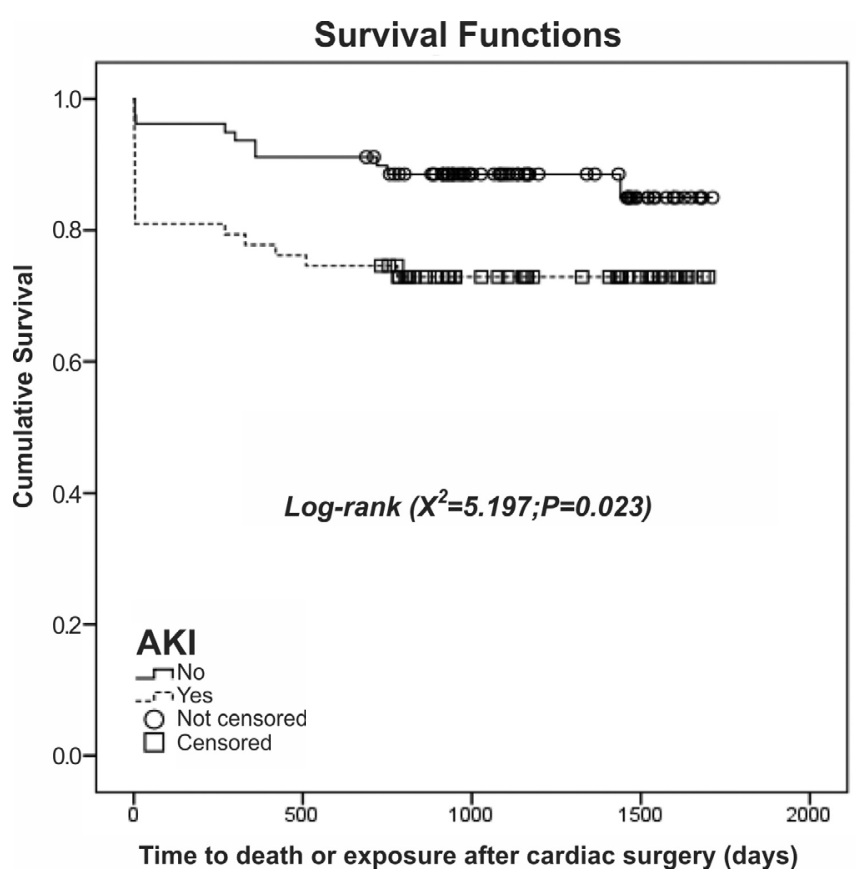

Fig. 1 - Survival analysis for individuals with and without acute kidney injury (AKI) after cardiac surgery. odds ratio estimation test showed that the risk of death was 2.5 times higher in the patients who developed AKI after cardiac surgery than in those who did not $(\mathrm{OR}=2.5,95 \% \mathrm{Cl}=1.06-6.00$, $P<0.04)$.

Consolidating the findings of our bivariate analysis, the Kaplan-Meier method demonstrated that in the first 30 days after surgery, individuals without AKI had a higher probability of survival, which persisted throughout the three-year followup period (Figure 1). The analysis of the risk of death (Figure 2) corroborated those findings, showing that individuals with AKI were more likely to die after cardiac surgery, either within the first 30 days after surgery or thereafter, than were those without AKI.

The Kaplan-Meier method showed that the survival rate was highest among the patients in which the AKI was classified as AKIN stage 1 and lowest among those in which it was classified as AKIN stage 3 (Figure 3). The Cox regression model showed that two variables had a negative impact on survival: having previously undergone cardiac surgery $(\mathrm{OR}=3.68,95 \% \mathrm{Cl}=1.09$ 12.37, $P<0.001)$; and requiring hemodialysis ( $O R=2.60,95 \%$ $\mathrm{Cl}=1.01-6.70, P<0.001)$.

\section{DISCUSSION}

In the present study, we found that the incidence of AKI after cardiac surgery was $43.66 \%$, much higher than the $16.4 \%$ and $15.7 \%$ reported by Andersson et al. ${ }^{[14]}$ and Kumada et al. ${ }^{[18]}$, respectively. That discrepancy could be attributed to the different definitions of AKI employed, variations in the methodologies, as well as in the patient profiles, and differences among the types of treatment facilities ${ }^{[6,19]}$. Our multivariate analysis showed that advanced age, valve replacement surgery, vasoactive drug use in the postoperative period, and having previously undergone cardiac surgery were the factors most strongly related to the development of AKI in a population from which patients with a creatinine clearance $<60 \mathrm{ml} / \mathrm{min}$ were excluded.

A progressive increase in the incidence of AKI among elderly 


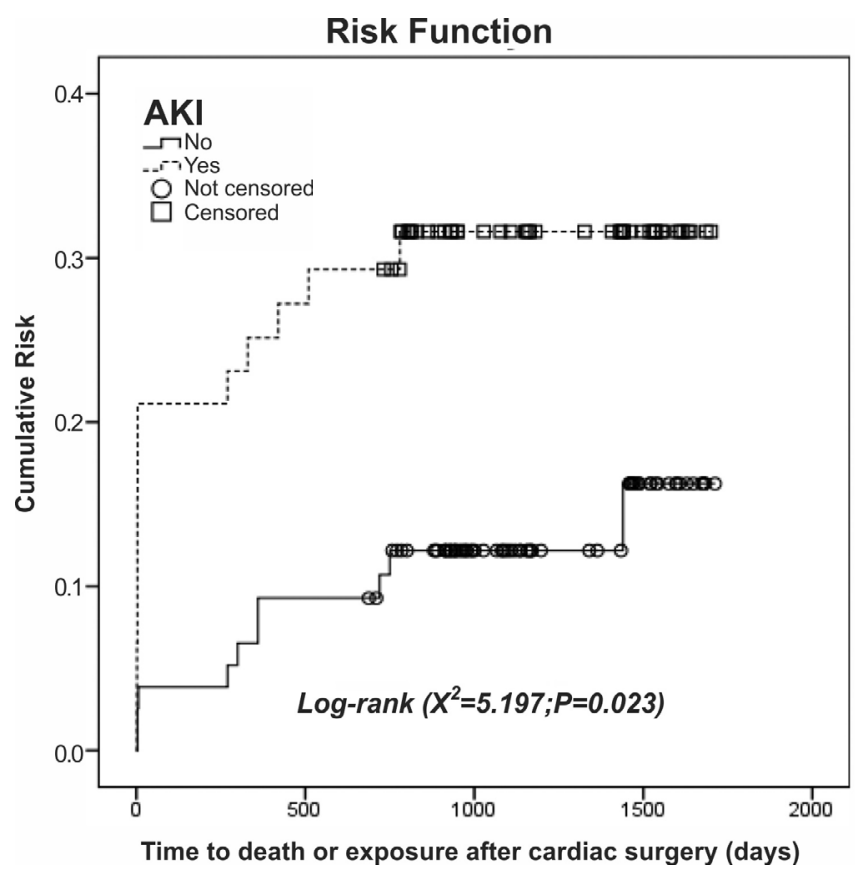

Fig. 2 - Analysis of early mortality among individuals with and without acute kidney injury (AKI) after cardiac surgery.

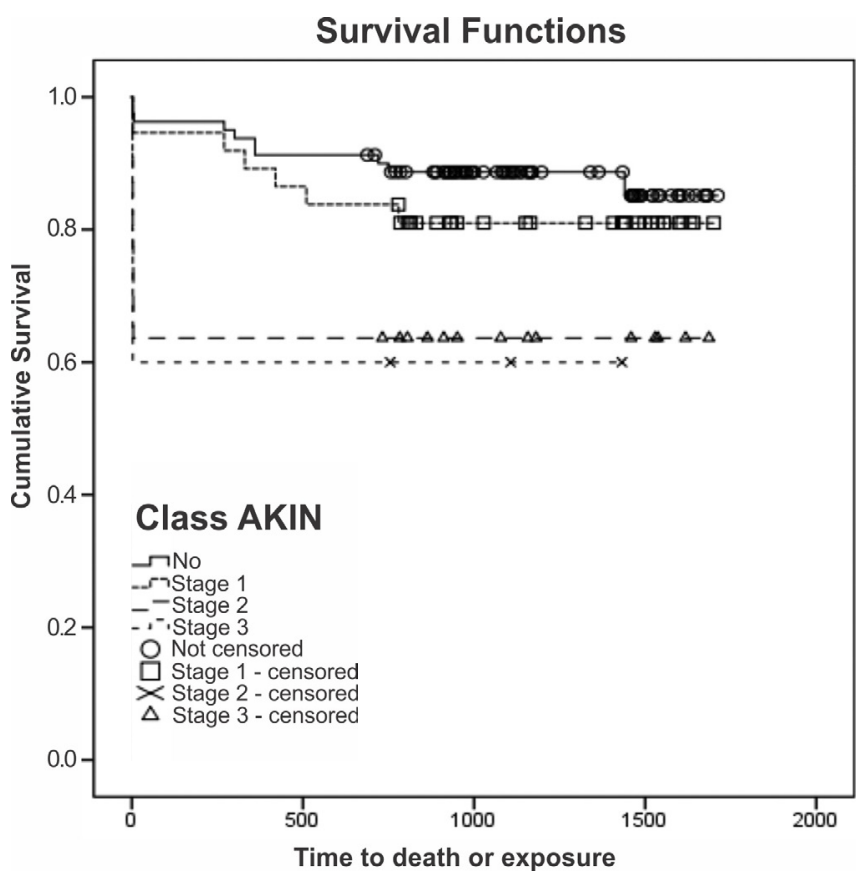

Fig. 3 - Analysis of survival according to the Acute Kidney Injury Network (AKIN) classification for acute kidney injury (AKI). patients has been reported in several studies ${ }^{[3,20]}$. According to Magro et al. ${ }^{[20]}$, that can be explained by the fact that the patients currently undergoing cardiac surgery are older and more critically ill than were those undergoing cardiac surgery in the past. Therefore, such patients have a worse prognosis and their recovery is delayed. Santos et al. ${ }^{[3]}$ found that being over 63 years of age is an independent risk factor for AKI. The loss of the renal functional reserve caused by the progressive reduction of the glomerular filtration rate with advancing age makes such patients more susceptible to renal damage when exposed to hypoperfusion ${ }^{[6,21,22]}$.

Our multivariate analysis demonstrated that patients undergoing surgery for valve replacement are at a greater risk of developing AKI than are those undergoing other types of cardiac surgery. Rodrigues et al. ${ }^{[23]}$ reported similar findings which can be explained by the fact that valve replacements are more complex procedures, with longer surgical times, which could have a direct effect on hemodynamic stability and on renal perfusion ${ }^{[23]}$. The idea of hemodynamic instability as the cause of AKI in valve replacement surgery was suggested in our study because dobutamine use in the postoperative period was found to be more common in valve replacements than in the other surgical procedures evaluated.

Our multivariate analysis showed that the patients who had previously undergone cardiac surgery were at a greater risk of developing AKI after a second cardiac surgery. In a study of 3,500 patients submitted to cardiac surgery, Karkouti et al. [24] demonstrated that surgical re-exploration is associated with a number of negative outcomes, including AKI. However, the mechanisms involved have not been well elucidated.

In our sample, the postoperative use of amines (norepinephrine and dobutamine) was found to predispose to the development of AKI. Pontes et al. ${ }^{[13]}$, Lopez-Delgado et al. ${ }^{[22]}$, and Santos et al. ${ }^{[3]}$ also demonstrated that the use of inotropic drugs in the postoperative period was a determining factor for the development of AKI. This is likely associated with the mechanisms of renal ischemia and reperfusion caused by poor cardiac performance and hemodynamic instability ${ }^{[3]}$.

Although several studies have shown that prolonged CPB is a major risk factor for $\mathrm{AKI}^{[14,22]}$, that variable was found to be of little importance in our study, probably because the mean duration of CPB was quite short. Some studies ${ }^{[12,24,25]}$ have shown that blood transfusion during the perioperative period increases the likelihood that AKI will occur after cardiac surgery. However, in the present study, perioperative blood transfusion was shown to be mildly renoprotective, regardless of the type of blood products used. We can hypothesize that the perioperative transfusion of blood products improved the hemodynamic status of the patients in our sample and was therefore protective against AKI.

In the present study, AKI had a negative impact on patient survival, an effect that was more pronounced in the more advanced AKIN stages and in patients requiring hemodialysis. Various studies have shown that the development of AKI after cardiac surgery increases mortality, especially in patients who require dialysis ${ }^{[13,22,23,26]}$. In a study involving 3,240 patients undergoing cardiac surgery, Hobson et al. ${ }^{[27]}$ also analyzed survival rates in those who developed $\mathrm{AKI}$ in the postoperative period, 
reporting that one-year and five-year survival rates were lower for the patients who developed AKI ( $89 \%$ and $44 \%$, respectively) than for those who did not ( $95 \%$ and $63 \%$, respectively). Loef et al. ${ }^{[28]}$ corroborated those findings in a cohort of 843 patients who underwent cardiac surgery and were followed for 100 months thereafter. The authors found that, during the follow-up period, mortality was significantly higher in patients with postoperative deterioration of renal function and that survival remained lower regardless of whether there was recovery of renal function after hospital discharge. The mechanisms involved in this process are not fully understood, because AKI can be an early sign that other systems and organs are also negatively affected, and the sum of those dysfunctions could contribute to and explain the higher mortality and lower survival among individuals developing AKI after cardiac surgery.

However, our study has certain limitations: It is a retrospective study. In addition, the size of the patient sample was small, along with the fact that all the surgical procedures were performed at a single center, which could have limited the statistical power of the study.

\section{CONCLUSION}

In the present study, we have shown that the occurrence of AKI after cardiac surgery had a negative influence on mortality and survival of the affected patients. Like other authors, we found that age, valve replacement, a history of cardiac surgery, and the use of vasoactive drugs in the postoperative period were independent predictors of the development of AKI after cardiac surgery in a population of patients with near-normal renal function. Thus, our findings underscore the importance of identifying risk factors for the development of AKI after cardiac surgery, which can further the development of effective renoprotective strategies.

\section{Authors' roles \& responsibilities}

KAR Substantial contributions to the conception or design of the work; or the acquisition, analysis, or interpretation of data for the work; final approval of the version to be published

CBD Substantial contributions to the conception or design of the work; or the acquisition, analysis, or interpretation of data for the work; final approval of the version to be published

\section{REFERENCES}

1. Fortes JV, Barbosa e Silva MG, BaldezTE, Costa MA, Silva LN, Pinheiro RS, et al. Mortality risk after cardiac surgery: application of Inscor in a University Hospital in Brazil's Northeast. Braz J Cardiovasc Surg. 2016;31 (5):396-9.

2. Kochi AC, Martins AS, Balbi AL, Moraes e Silva MA, Lima MC, Martins $L C$, et al. Preoperative risk factors for the development of acute renal failure in cardiac surgery. Rev Bras Cir Cardiovasc. 2007:22(1):33-40.
3. Santos FO, Silveira MA, Maia RB, Monteiro MD, Martinelli R. Acute renal failure after coronary artery bypass surgery with extracorporeal circulation: incidence, risk factors, and mortality. Arq Bras Cardiol. 2004;83(2):150-4.

4. Chertow GM, Burdick E, Honour M, Bonventre JV, Bates DW. Acute kidney injury, mortality, length of stay, and costs in hospitalized patients. J Am Soc Nephrol. 2005;16(11):3365-70.

5. Conlon PJ, Stafford-Smith M, White WD, Newman MF, King S, Winn MP, et al. Acute renal failure following cardiac surgery. Nephrol Dial Transplant. 1999;14(5):1158-62.

6. Corredor C, Thomson R, Al-Subaie N. Long-term consequences of acute kidney injury after cardiac surgery: a systematic review and meta-analysis. J Cardiothorac Vasc Anesth. 2016;30(1):69-75.

7. Mehta RL. Acute renal failure and cardiac surgery: marching in place or moving ahead? J Am Soc Nephrol. 2005;16(1):12-4.

8. Chertow GM, Lazarus JM, Christiansen CL, Cook EF, Hammermeister $\mathrm{KE}$, Grover F, et al. Preoperative renal risk stratification. Circulation. 1997;95(4):878-84.

9. Jiang W, Xu J, Shen B, Wang C, Teng J, Ding X. Validation of four prediction scores for cardiac surgery-associated acute kidney injury in Chinese patients. Braz J Cardiovasc Surg. 2017;32(6):481-6.

10. Ferreiro A, Lombardi R. Acute kidney injury after cardiac surgery is associated with mid-term but not long-term mortality: a cohort-based study. PLoS One. 2017;12(7):e0181158.

11. Ortega-Loubon C, Fernández-Molina M, Carrascal-Hinojal Y, FulquetCarreras E. Cardiac surgery-associated acute kidney injury. Ann Cardiac Anaesth. 2016;19(4):687-98.

12. De Santo LS, Romano G, Mango E, lorio F, Savarese L, Numis F, et al. Age and blood transfusion: relationship and prognostic implications in cardiac surgery. J Thorac Dis. 2017;9(10):3719-27.

13. Pontes JC, Silva GV, Benfatti RA, Machado NP, Pontelli R, Pontes ER. Risk factors for the development of acute renal failure following on-pump coronary artery bypass grafting. Rev Bras Cir Cardiovasc. 2007;22(4):484-90.

14. Andersson LG, Ekroth R, Bratteby LE, Hallhagen S, Wesslén O. Acute renal failure after coronary surgery: a study of incidence and risk factors in 2009 consecutive patients. Thorac Cardiovasc Surg. 1993;41(4):237-41.

15. Jyrala A, Weiss RE, Jeffries RA, Kay GL. Effect of mild renal dysfunction (s-crea 1.2-2.2 mg/dl) on presentation characteristics and short- and long-term outcomes of on-pump cardiac surgery patients. Interact Cardiovasc Thorac Surg. 2010;10(5):777-82.

16. Santana-Santos E, Marcusso ME, Rodrigues AO, Queiroz FG, Oliveira $L B$, Rodrigues AR, et al. Strategies for prevention of acute kidney injury in cardiac surgery: an integrative review. Rev Bras Ter Intensiva. 2014;26(2):183-92

17. Lopes JA, Fernandes P, Jorge S, Gonçalves S, Alvarez A, Costa e Silva Z, et al. Acute kidney injury in intensive care unit patients: a comparison between the RIFLE and the Acute Kidney Injury Network classifications. Crit Care. 2008;12(4):R110.

18. Kumada Y, Yoshitani K, Shimabara Y, Ohnishi Y. Perioperative risk factors for acute kidney injury after off-pump coronary artery bypass grafting: a retrospective study. JA Clin Rep. 2017;3(1):55.

19. Nina VJ, Matias MM, Brito DJ, Figueiredo Neto JA, Coutinho LB, Rodrigues RF, et al. Acute kidney injury after coronary artery bypass grafting: assessment using RIFLE and AKIN criteria. Rev Bras Cir Cardiovasc. 2013;28(2):231-7.

20. Magro MC, Franco ES, Guimarães D, Kajimoto D, Gonçalves MA, Vattimo MF. Evaluation of the renal function in patients in the postoperative period of cardiac surgery: does AKIN classification predict acute kidney dysfunction? Rev Bras Ter Intensiva. 2009;21(1):25-31.

21. Srivastava V, D'Silva C, Tang A, Sogliani F, Ngaage DL. The impact of major perioperative renal insult on long-term renal function and survival after cardiac surgery. Interact Cardiovasc Thorac Surg. 2012;15(1):14-7. 
22. Lopez-Delgado JC, Esteve F, Torrado H, Rodríguez-Castro D, Carrio ML, Farrero $E$, et al. Influence of acute kidney injury on short- and longterm outcomes in patients undergoing cardiac surgery: risk factors and prognostic value of a modified RIFLE classification. Critical Care. 2013;17(6):R293.

23. Rodrigues AJ, Evora PR, Bassetto S, Alves Júnior L, Scorzoni Filho A, Araujo WF, et al. Risk factors for acute renal failure after heart surgery. Rev Bras Cir Cardiovasc. 2009;24(4):441-6.

24. Karkouti K, Wijeysundera DN, Yau TM, Callum JL, Cheng DC, Crowther $M$, et al. Acute kidney injury after cardiac surgery: focus on modifiable risk factors. Circulation. 2009;119(4):495-502.

25. Kuduvalli M, Oo AY, Newall N, Grayson AD, Jackson M, Desmond MJ, et al. Effect of peri-operative red blood cell transfusion on 30-day and 1-year mortality following coronary artery bypass surgery. Eur J Cardiothorac Surg. 2005;27(4):592-8.

26. Lassnigg A, Schmidlin D, Mouhieddine M, Bachmann LM, Druml W, Bauer $\mathrm{P}$, et al. Minimal changes of serum creatinine predict prognosis in patients after cardiothoracic surgery: a prospective cohort study. J Am Soc Nephrol. 2004;15(6):1597-605.

27. Hobson CE, Yavas S, Segal MS, Schold JD, Tribble CG, Layon AJ, et al. Acute kidney injury is associated with increased long-term mortality after cardiothoracic surgery. Circulation. 2009;119(18):2444-53.

28. Loef BG, Epema AH, Smilde TD, Henning RH, Ebels T, Navis G, et al. Immediate postoperative renal function deterioration in cardiac surgical patients predicts in-hospital mortality and long-term survival. J Am Soc Nephrol. 2005;16(1):195-200. 